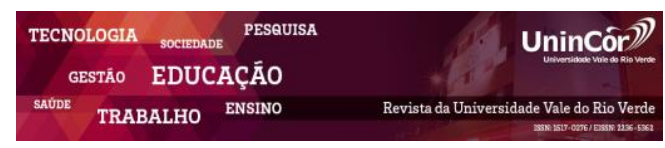

Revista da Universidade Vale do Rio Verde ISSN: 1517-0276 / EISSN: 2236-5362 v. $16 \mid \mathbf{n}^{\circ} .3$ | Ano 2018

Gustavo Matheus Julião Campos Universidade Vale do Rio Verde (UninCor) gustavomatheus.crv@ hotmail.com

Eliana Alcantra

Universidade Vale do Rio Verde (UninCor) prof.eliana.alcantra@unincor.edu.br

Ramiro Machado Rezende Universidade Vale do Rio Verde (UninCor) prof.ramiro.rezende@unincor.edu.br

\section{LEVANTAMENTO DE INSETOS-PRAGA NA CULTURA DA SOJA}

\section{RESUMO}

Com o objetivo de avaliar a ocorrência de insetos-praga na cultura da soja realizou-se este trabalho, na safra de 2016/2017, em uma área de 1,6 ha, localizada na Fazenda Lopinho, no município de Conceição do Rio Verde/MG. Para isso, foram demarcados seis pontos amostrais e realizados levantamentos semanais de espécies de insetos na área. Os insetos foram capturados com auxílio de pano de batida com dimensão de $1 \mathrm{~m}$ x $1 \mathrm{~m}$. Em cada ponto, foram capturadas e contabilizadas lagartas, percevejos e, encontrados também, insetos considerados pragas secundárias da cultura, como por exemplo, a vaquinha (Diabrotica speciosa) e o idiamin (Lagria villosa). Depois de contados, os insetos foram colocados em recipientes contendo álcool $70 \%$ devidamente identificados com data e ponto. Foi observado um aumento no número de insetos nas fases finais do ciclo da soja e também após as aplicações de inseticidas. Foram encontrados percevejos Piezodorus guildinii e Euschistus heros e lagartas Pseudoplusia includens. Picos populacionais desses insetos foram observados nos estádios fenológicos V2, V5, R3 e R5. As informações sobre a ocorrência de insetos na lavoura são de suma importância, pois por meio da amostragem pode-se ter um melhor posicionamento para o momento exato de entrar com o controle.

Palavras-chave: Glycine max. Insecta. Monitoramento. Pano de batida.

\section{SURVEY OF PEST INSECTS IN SOYBEAN}

\begin{abstract}
In order to evaluate the occurrence of pest insects in soybean, this study was carried out in the 2016/2017 harvest in an area of 1.6 ha, located in Lopinho Farm, in the municipality of Conceição do Rio Verde/MG. Six sampling points were demarcated and weekly surveys of insect species in the area were performed. The insects were captured using a beating cloth of $1 \times 1 \mathrm{~m}$ size. At each point, were captured and counted caterpillars, bugs, and insects considered as secondary pests of the crop such as Diabrotica speciosa and Lagria villosa. After counting, the insects were placed in containers containing $70 \%$ alcohol duly identified with date and point. An increase in the number of insects was observed in the final stages of the soybean cycle and after the application of insecticides. Bugs (Piezodorus guildinii and Euschistus heros) and caterpillars (Pseudoplusia includes) were found. Population peaks of these insects were observed in the phenological stages V2, V5, R3 and R5. The information on the occurrence of insects in the crop is of great importance, since through the sampling, it is possible to establish the exact moment for initiate the control.
\end{abstract}

Keywords: Glycine max. Insecta. Monitoring. Beating cloth. 


\section{INTRODUÇÃO}

A soja (Glycine $\max (\mathrm{L})$ Merrill) é uma planta herbácea, da classe Rosideae, ordem Fabales e família Fabaceae. As principais variedades encontradas no mercado apresentam caule híspido, pouco ramificado e raiz com eixo principal e muitas ramificações. As folhas são trifolioladas e apresentam flores com fecundação autógama (AGÊNCIA EMBRAPA, 2017).

A cultura da soja desempenha importante papel nas exportações do mercado brasileiro tornando esta cultura uma commoditie agrícola de grande importância. No Brasil, a produção de soja alcançou recorde de 118,9 milhões de toneladas na safra 2017/2018, 4,2\% superior à safra anterior (CONAB, 2018). A área semeada está em torno de 35,1 milhões de hectares na safra 2018/2019, um ganho absoluto de 1,2 milhão de hectares, o maior entre todas as culturas avaliadas (CONAB, 2018).

O fator que limita a produção de soja são os problemas fitossanitários, como a presença de organismos que podem causar algum dano ao meio ambiente. Na cultura da soja parte desses problemas são decorrentes da presença de insetos como as lagartas Anticarsia gemmmatalis, Pseuplusia includens e percevejos Piezodorus guldinii, Nezara viridula e Euschistus heros (GALLO et al., 2002).

A lagarta da soja A. gemmatalis, pragachave da cultura, possui coloração verde, movimenta-se assemelhando a falsa medideira (mede palmo) e possui cinco pares de pernas abdominais (EMBRAPA SOJA, 2016). É considerada a principal praga desfolhadora da soja, tornando um risco a todas as lavouras (GAZZONI e YORINIORI, 1995; MOSCARDI e SOUZA, 2002), pois se alimenta do limbo foliar podendo causar redução de até $100 \%$ da área foliar (LOURENÇÃO et al., 2010).

A espécie $P$. includens era considerada praga secundária da soja, devido seu controle ser feito naturalmente por meio de parasitoides. Entretanto, com o crescimento do plantio direto no Brasil, vários produtores têm aplicado herbicidas pós emergentes, fazendo mistura de herbicidas com outros produtos, tais como inseticidas. Consequentemente, ocorre um desequilíbrio nas populações de inimigos naturais, favorecendo o aumento na população dessa praga. Além disso, esse aumento também é devido à própria aplicação de inseticidas (BUENO et al. 2009).

O percevejo E. heros vem se destacando pelo seu aumento nas últimas décadas, principalmente pelo seu aumento populacional e a sua distribuição geográfica (CORRÊAFERREIRA \& PANIZZI 1999).

A intensidade do dano causado por percevejos depende da espécie e estádio de desenvolvimento da cultura (CORREAFERREIRA \& KRZYZANOWSKI, 2009). No período de enchimento de grãos (fases R5 e R6), os percevejos são encontrados em maior número na cultura da soja (CORRÊA-FERREIRA, 2005). Os percevejos se alimentam das plantas causando atrofiamento dos grãos, com consequente redução em seu peso e qualidade (CORRÊA-FERREIRA \& AZEVEDO, 2002; 
BELORTE et al., 2003). Atualmente, o percevejo marrom (E. heros) é considerado a principal espécie de percevejo da soja, além de ser praga chave da cultura (GODOY et al., 2010). No período de enchimento de grãos, esses percevejos podem ser encontrados em maior número na cultura da soja (CORRÊAFERREIRA, 2005).

A vaquinha (Diabrotica speciosa) também é uma praga de grande importância e tida como uma das espécies fitófagas mais comuns em várias culturas, sendo causadora de muitos danos (VENTURA et al., 2001).

Uma das alternativas para diminuir as aplicações de inseticidas é realizar o monitoramento da lavoura por meio de amostragens (BUENO et al., 2013). Para o levantamento dos insetos existem várias formas de amostragem, variando conforme a cultura, os estádios fenológicos e o custo desses métodos (WADE et al., 2006). Outro fator importante para monitorar os insetos-praga da soja (lagartas e percevejos, principalmente) é quantificar o número de espécies na área, para que sejam tomadas as decisões corretas sobre o manejo destes (REUNIÃO DE PESQUISA DE SOJA DA REGIÃO SUL, 2012).

Diante do exposto, realizou-se este trabalho com o objetivo de identificar e contabilizar os insetos-praga da soja utilizando pano de batida durante o ciclo de desenvolvimento da cultura.

\section{MATERIAL E MÉTODOS}

O experimento foi conduzido na Fazenda Lopinho (área total de 600 ha) localizada no município de Conceição do Rio Verde/MG ( $21^{\circ} 55^{\prime} \mathrm{W}$ e $\left.45^{\circ} 06^{\prime} \mathrm{S}\right)$. A área experimental situase a $926 \mathrm{~m}$ de altitude e apresenta média pluviométrica acumulada ao longo dos últimos oito anos de $1.655,7 \mathrm{~mm}$.

$\mathrm{Na}$ área experimental, o cultivo de soja vinha sendo realizado durante quatro anos com sucessão de cultura soja/milho.

A área para a realização do levantamento dos insetos (1,6 ha) foi dividida em seis pontos amostrais aleatoriamente.

A cultivar de soja plantada foi a 95R51, com ciclo de 105 dias e resistente ao herbicida Roundup $^{\circledR}$. A semeadura ocorreu no dia 20/10/2016 com espaçamento de $0,60 \mathrm{~cm}$.

Os tratos culturais utilizados foram aqueles recomendados para a cultura segundo orientações técnicas. Para a adubação utilizou-se a formulação NPK 9-43-00 (200 kg ha-1) e cloreto de potássio $\left(200 \mathrm{~kg} \mathrm{ha}^{-1}\right)$, sendo aplicados antes do plantio.

Para derrubada e coleta dos insetos nos pontos amostrais o método utilizado foi o do pano de batida (pano branco com dimensões de $1 \mathrm{~m} \times 1 \mathrm{~m}$ e com as extremidades fixadas em cabos de madeira) (STÜRMER et al., 2012).

Para a cultura da soja recomenda-se a utilização de pano de batida, sendo três as formas de utilização: pano de batida (BOYER \& DUMAS, 1969) (Figura 1A), pano de batida largo (CORRÊA FERREIRA, 2005) (Figura 1B) e pano de batida vertical (DREES \& RICE, 1985) (Figura 1C). 

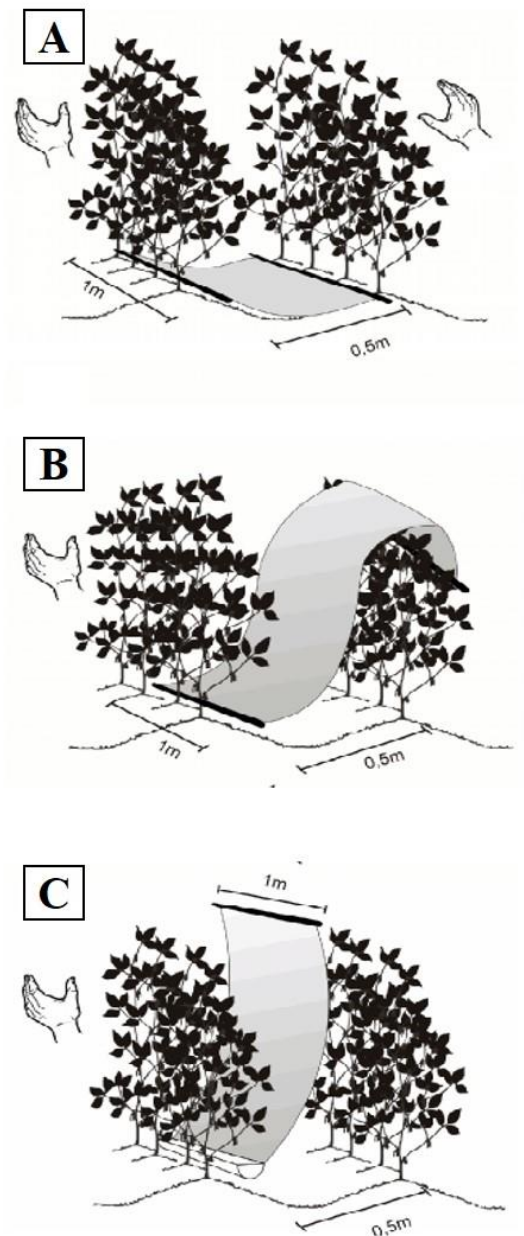

Figura 1. Representação do pano de batida (A), pano de batida largo (B) e pano de batida vertical (V) utilizados como método de amostragem de lagartas e percevejos na cultura da soja.

No presente trabalho a forma escolhida foi a de pano de batida. As primeiras amostragens foram realizadas doze dias após o plantio (estádio V1). Após 18 dias do plantio, foi realizada a aplicação de inseticida (Metomil 107,2 g i.a ha ${ }^{-1}$ ) para controle das lagartas $A$. gemmatalis e $P$. includens não respeitando o nível de controle para lagartas desfolhadoras.

Os insetos amostrados foram coletados e armazenados em recipientes de plástico contendo álcool $70 \%$, sendo devidamente identificados com data e pontos de coleta. Após as coletas os insetos foram levados ao Laboratório de Entomologia da Universidade Vale do Rio Verde, Três Corações/MG para identificação com auxílio de microscópio estereoscópio e literatura especializada.

Os dados do levantamento e identificação dos insetos foram anotados em planilhas de identificação para análise descritiva e comparativa. Essas planilhas foram confeccionadas de forma simples contendo o nome do inseto, em que ponto amostral foi coletado e a data de amostragem do mesmo modo que foram identificados nos frascos com álcool.

\section{RESULTADOS E DISCUSSÃO}

$\mathrm{Na}$ área de estudo foram encontradas cinco espécies de insetos-praga da soja, sendo duas espécies de percevejos considerados pragaschave (Euschistos heros) e (Piezodorus guildinii) e três espécies consideradas pragas secundárias como a lagarta Pseudoplusia includens, a vaquinha (Diabrotica speciosa) e o idiamin (Lagria villosa) (Figura 2).

No total foram coletados 109 insetos pertencentes a cinco espécies, sendo a lagarta Pseudoplusia includens a mais encontrada (67,89\%), seguida de L. vilosa (11,93\%), D. speciosa $(10,09 \%)$, E. herus $(9,17 \%)$ e $P$. guildini. 


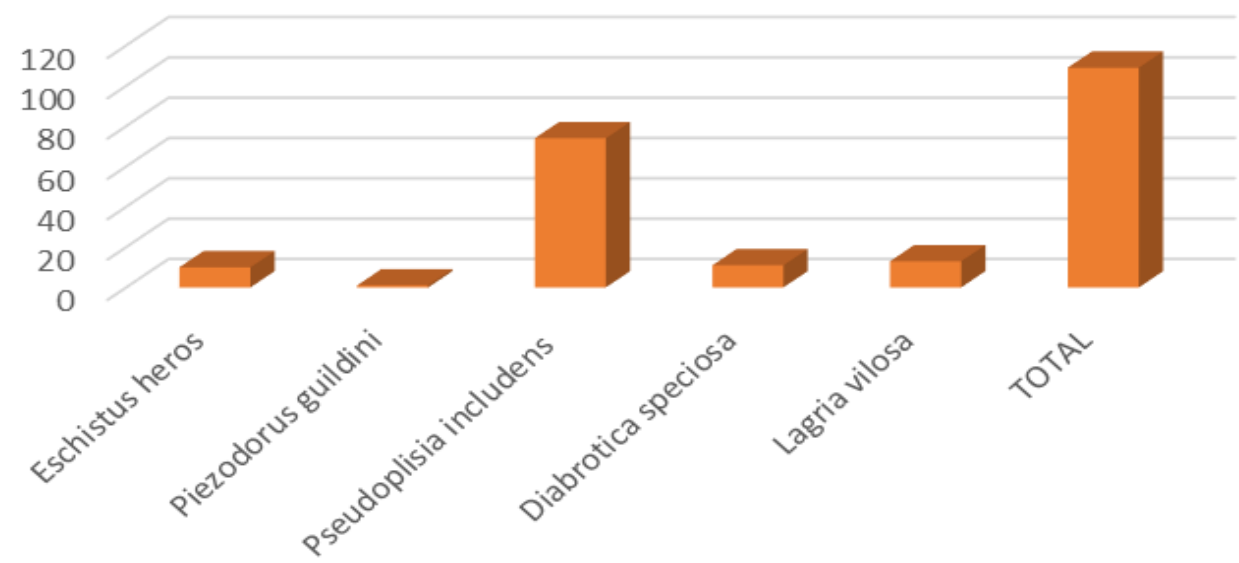

Figura 2. Número de insetos praga amostrados por pano de batida em lavoura de soja em área do município de Conceição do Rio Verde/MG, na safra 2016/2017.

Foi constatado a ocorrência de insetos praga na cultura da soja ao longo das avaliações, exceto nas duas primeiras (Figura 3). Ao relacionar o número de insetos-praga com o estádio fenológico da soja observaram-se picos populacionais das espécies amostradas nas fases V2, V5, R3 e R5. O estádio R3 representou o estádio de maior ocorrência de insetos-praga. Esse é o período que compreende o aparecimento dos legumes e é considerado o período crítico para o ataque de insetos como os percevejos (CORRÊA FERREIRA \& AZEVEDO, 2002 apud STÜRMER et al., 2012).

Nas fases iniciais da cultura houve pequeno número de insetos-pragas chave da cultura, predominando a ocorrência de pragas secundárias como D. speciosa e L. villosa, e presença de maior número de lagartas nas fases reprodutivas.

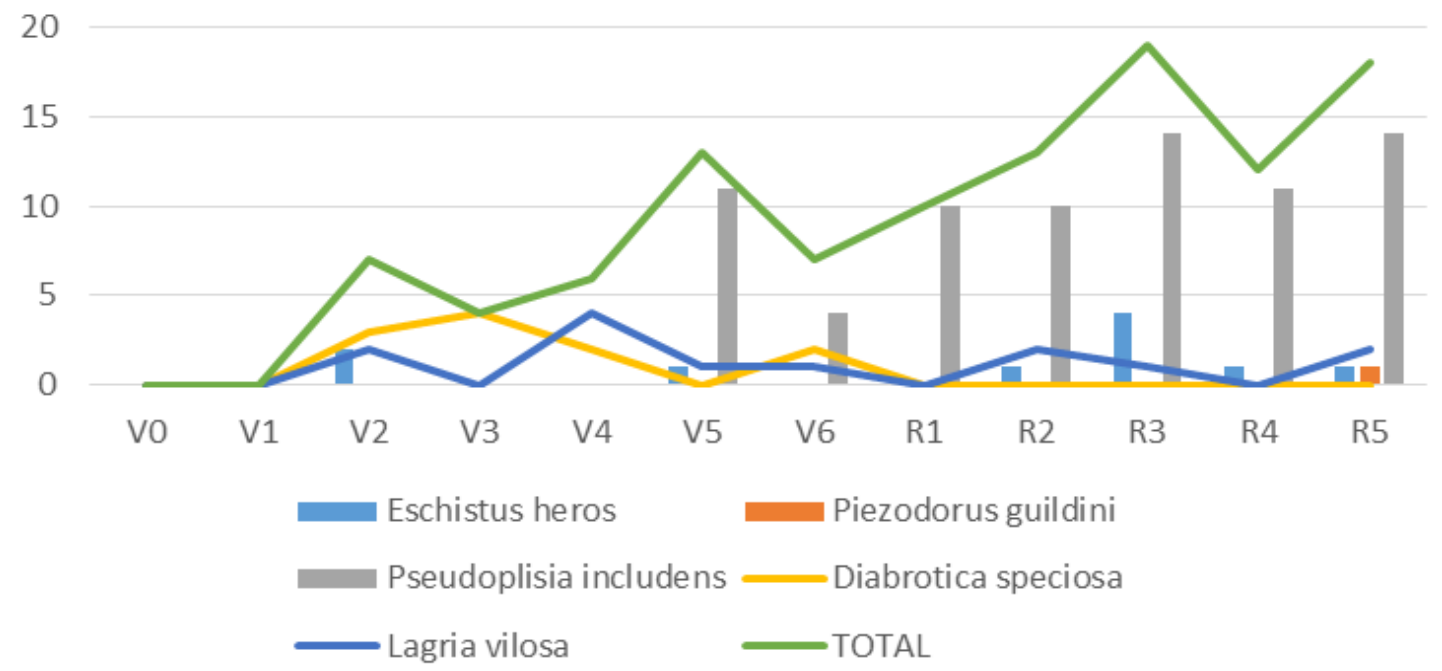

Figura 3. Principais espécies de insetos-praga amostradas por pano de batida em lavoura de soja em área do município de Conceição do Rio Verde/MG, na safra 2016/2017. 
A partir do final da fase vegetativa e sua transição para a reprodutiva houve ocorrência e o aumento do número de lagartas e percevejos. Esse fato também foi observado por Sturmer et al. (2012) na cultura da soja.

$\mathrm{Na}$ fase reprodutiva houve maior ocorrência de percevejos, sendo E. heros a espécie encontrada em maior número, fato relatado também nos estudos de Lourenção et al. (1999). A espécie $P$. guildini também foi encontrada, ambas são consideradas pragas-chave da soja. Os danos causados por percevejos interferem diretamente na produção, pois estes sugam os grãos (BELORTE et al., 2003). No presente trabalho, os percevejos, principalmente E. heros, foram observados nos estádios R3 até uma semana antes da colheita. A ausência desses insetos nos estádios anteriores à R3 mostra que essa fase não se apresenta como alimento preferencial aos percevejos (CORRÊA FERREIRA, 2005).

Após aplicações de inseticidas na área o número de percevejos atingiu o nível de controle, que são dois percevejos por $\mathrm{m}^{2}$, caracterizando resistência desses insetos ao controle químico.

A partir do estádio V5 o número de lagartas foi aumentando a cada amostragem, diferente do trabalho de Lourenção et al. (2010), no qual verificaram maior infestação de lagartas nos estádios reprodutivos. Este resultado pode estar relacionado ao ciclo da cultivar, sendo a cultivar utilizada neste trabalho de ciclo semiprecoce (105 dias) e a do estudo comparativo uma cultivar de ciclo precoce.

As lagartas $P$. includens ocorreram em maior intensidade na fase R3.

Observou-se também a ocorrência de insetos não considerados pragas da soja, como o $L$. villosa e D. speciosa, sendo estas consideradas pragas do feijoeiro. Esse aparecimento de insetos considerados pragas secundárias está relacionado principalmente ao manejo da cultura ou do solo (EMBRAPA, 2007).

\section{CONCLUSÃO}

Foi constatada a presença dos percevejos E. heros e P. guildini, da lagarta P. includens e dos besouros $L$. vilosa e $D$. speciosa na cultura da soja.

O estádio fenológico da soja R3 representa a fase de maior ocorrência da lagarta $P$. includens e do percevejo E. herus.

\section{REFERÊNCIAS}

CONAB - COMPANHIA NACIONAL DE ABASTECIMENTO. Observatório agrícola: acompanhamento da safra brasileira, Décimo Levantamento, v.5, n.10, 2018.

NEPOMUCENO, A.L.; FARIAS, J.R.B.; NEUMAIER, N. Características da soja. AGÊNCIA EMBRAPA DE INFORMAÇÃO TECNOLÓGICA. Disponível em:

<http://www.agencia.cnptia.embrapa.br/gestor/soja/ar vore/CONTAG01_24_271020069131.html>. Acesso em: 26 jan. 2019.

BELORTE, L.C.; RAMIRO, Z.A.; FARIA, A.M.; MARINO, C.A.B. Danos causados por percevejos (Hemiptera: Pentatomidae) em cinco cultivares de soja (Glycine $\max (\mathrm{L}$.) Merrill, 1917) no Município de Araçatuba, SP. Arquivos Instituto Biológico, v.70, n. 2, p.169-175, 2003.

BOYER, W.P.; DUMAS, B.A. Plant shaking methods for soybean insect survey in Arkansas. In:__. Survey methods for some economic insects. USA: Dep. Agric Res Ser, 1969. p. 92-94.

BUENO, A. F. et al. Limiares econômicos no gerenciamento de pragas integradas na soja: antigos conceitos, adoção atual e adequação. Neotropical Entomology, v.42, p.439-447, 2013.

BUENO, R.C.O.F.; PARRA, J.R.P.; BUENO, A.F.; HADDAD, M.L. Desempenho de tricigramatídeos 
como potenciais agentes de controle de Pseudoplusia includens Walker (Lepidoptera: Noctuidae.).

Neotropical Entomology, v.38, n.3, p.389-394, 2009.

CORRÊA-FERREIRA, B.S.; AZEVEDO, J. Soybean seed damage by different species of stinkbugs.

Agriculture and Forest Entomology, v.4, p.145-150, 2002 .

CORRÊA-FERREIRA, B. S. Suscetibilidade da soja a percevejos na fase anterior ao desenvolvimento das vagens. Pesquisa Agropecuária Brasileira, v. 40, n. 11, p. 1067-1072, 2005.

CORRÊA-FERREIRA,B.S; KRZYZANOWSKI, F.C; MINAMI, C.A. Percevejos e qualidade de sementes de soja - Série Sementes. Londrina: Embrapa Soja 2009.15p. (Circular Técnica, 67).

CORRÊA-FERREIRA, B.S; PANIZZI, A.R.

Percevejos da soja e seu manejo - Londrina:

Embrapa Soja 1999.45p.( Circular Técnica,24)

DREES, B.M.; RICE, M.E. The vertical beat sheet: a new device for sampling soybean insects. Journal of Economic Entomology, v.78, p.1507-1510, 1985.

EMBRAPA. Soja, Londrina: Informativo Eletrônico, 2016. Disponível em:

$<$ http://www.embrapa.br/soja/cultivos/soja1. Acesso em 17 de abril de 2018.

GALLO, D. et al. Entomologia agrícola. Piracicaba: FEALQ, 2002. v. 10.

GAZZONI, D.L.; YORINORI, J.T. Manual de identificação de pragas e doenças da soja. Brasília, 1995.

GODOY, K.B.; AVILA, C.J.; DUARTE, M.M.; ARCE, C.C.M. Parasitismo e sítios de diapausa de adultos do percevejo marrom, Euschistus heros na região da Grande Dourados, MS. Ciência Rural, v.40, n. 5, p. 1199-1202, 2010.

LOURENÇÃO, A.L.; PEREIRA, J.C.V.N.A.; MIRANDA, M.A.C.; AMBROSANO, G.M.B. Danos de percevejos e de lagartas em cultivares e linhagens de soja de ciclos médio e semi-tardio. Anais da Sociedade Entomológica do Brasil, v.28, p.157-167, 1999.

LOURENÇÃO, A.L.; RECO, P.C.; BRAGA, N.R.; DO VALLE, G.; PINHEIRO, J.B. Produtividade de genótipos de soja sob infestação da lagarta-da-soja e de percevejos. Neotropical Entomology, v.39, p.275$281,2010$.

MOSCARDI, F.; SOUZA, M.L. Baculovírus para o controle de pragas: panaceia ou realidade? Revista
Biotecnologia Ciência \& Desenvolvimento, v.24, p.21-29, 2002.

REUNIÃO DE PESQUISA DE SOJA DA REGIÃO SUL, Passo Fundo: EMBRAPA, 2012. ISSN 19840713. Disponível em: <

https://ainfo.cnptia.embrapa.br/digital/bitstream/item/7 9907/1/atas-e-resumos-reuniao-soja-2012.pdf>.

Acesso em: 14 fev. 2019.

STÜRMER, G.R.; CARGNELUTTI FILHO, A.; STEFANELO, L.S.; GUEDES, J.V.C. Eficiência de métodos de amostragem de lagartas e de percevejos na cultura da soja. Ciência Rural, v.42, n.12, p. 2105 2111, 2012.

VENTURA, M.U.; MELLO, E.P.; OLIVEIRA, A.R.M.; SIMONELLI, F.; MARQUES, F.A.; ZARBIN, P.H.G. Males are attracted by females traps: A new perspective for management of Diabrotica speciosa (Germar) (Coleoptera: Chrysomelidae) using sexual pheromone. Neotropical Entomology, v.30, p 361-364, 2001.

WADE, M.R.; SCHOLZ, B.C.G.; LLOYD, R.J.; CLEARY, A.J.; FRANZMANN, B.A.; ZALUCKI, M.P. Temporal variation in arthropod sampling effectiveness: the case for using the beat sheet method in cotton. Entomologia Experimentalis et Applicata, v.120, p.139-153, 2006.

Gustavo Matheus Julião Campos

Graduando em Agronomia, Universidade Vale do Rio Verde (UninCor)

\section{Eliana Alcantra}

Professora, Universidade Vale do Rio Verde (UninCor)

Ramiro Machado Rezende

Professor, Universidade Vale do Rio Verde (UninCor) 
